\title{
Laser-Induced Fluorescence of Molybdenocene and Tungstenocene in Low-Temperature Matrices
}

\author{
Jeremy N. Hill, Robin N. Perutz, ${ }^{*}$ and A. Denise Rooney ${ }^{1}$ \\ Department of Chemistry, University of York, York YO1 SDD, U.K.
}

Received: June 20, $1994^{\otimes}$

\begin{abstract}
The reactive metallocenes, tungstenocene and molybdenocene $\left(\mathrm{M}\left(\eta^{5}-\mathrm{C}_{5} \mathrm{H}_{5}\right)_{2} ; \mathrm{M}=\mathrm{Mo}, \mathrm{W}\right)$, have been generated by photolysis of the corresponding dihydride complexes, $\mathrm{M}\left(\eta^{5}-\mathrm{C}_{5} \mathrm{H}_{5}\right)_{2} \mathrm{H}_{2}$, in argon and nitrogen matrices at $12 \mathrm{~K}$. The metallocenes have been probed by laser-induced fluorescence with a pulsed tunable laser and by UV/vis absorption spectroscopy. Structured emission is observed from the LMCT excited states (lifetimes $<10 \mathrm{~ns}$ ). The spectra are complicated by multiple sites/conformers, but emission spectra of a single site/ conformer may be obtained with appropriate selection of matrix and excitation wavelength. Corresponding excitation spectra are measured from the area of selected emission peaks as a function of excitation wavelength. Vibrational progressions are dominated by the ring-metal-ring symmetric stretching mode $\left(v_{4} \approx 300 \mathrm{~cm}^{-1}\right)$. Nevertheless, this mode changes in frequency by $\leq 4 \mathrm{~cm}^{-1}(\leq 1.3 \%)$ in the LMCT excited state. The bestresolved peaks have a full width at half-maximum of ca. $10 \mathrm{~cm}^{-1}$. Most of the emission is vibrationally fully relaxed, but weak emission peaks arising from $v^{\prime}=1$ states are found for $\mathrm{MoCp}_{2}$ in $\mathrm{N}_{2}$ matrices.
\end{abstract}

\section{Introduction}

In spite of the immense number of investigations of the photochemistry of organometallics, spectroscopic information on excited states is very restricted. ${ }^{2}$ The power of laser-induced fluorescence (LIF) as a probe to determine excited-state and ground-state properties of matrix-isolated open-shell metallocenes was demonstrated in the preceding paper through the example of rhenocene. ${ }^{3}$ We now use the same techniques to examine the $\mathrm{d}^{4}$ metallocenes, molybdenocene and tungstenocene $\left(\mathrm{MCp}_{2} ; \mathrm{M}=\mathrm{Mo}, \mathrm{W} ; \mathrm{Cp}=\eta^{5}-\mathrm{C}_{5} \mathrm{H}_{5}\right)$. Both $\mathrm{WCp}_{2}$ and $\mathrm{MoCp} 2$ have been implicated in numerous photochemical reactions in solution. ${ }^{4}$ Here, these two molecules are generated by photolysis of the corresponding dihydride complexes, $\mathrm{MCp}_{2} \mathrm{H}_{2}$, in argon and nitrogen matrices. They have already been the subject of extensive study by matrix isolation with detection by IR and UV/vis absorption spectroscopy and by magnetic circular dichroism (MCD)..$^{4-7}$ They have a ground electron configuration $\mathrm{e}_{2}{ }^{3} \mathrm{a}_{1}{ }^{1}$, leading to a ${ }^{3} \mathrm{E}_{2}$ ground electronic state. In the case of $\mathrm{WCp}_{2}$, spin-orbit coupling quenches any Jahn-Teller splitting, leading to a well-defined $E_{2}(\Omega=3)$ ground spinorbit state. An electronic IR transition to a higher spin-orbit state is prominent. For $\mathrm{MoCp}_{2}$, the Jahn-Teller effect and spin-orbit coupling are of comparable magnitude, resulting in broader IR bands than for $\mathrm{WCp}_{2}$ and no IR electronic transition. Both molecules exhibit an intense LMCT absorption band with onset at ca. 400 and $420 \mathrm{~nm}$ for $\mathrm{WCp}_{2}$ and $M o \mathrm{Cp}_{2}$, respectively. The upper state has been demonstrated to be of $E_{2}$ symmetry by MCD. The background to the vibrational spectroscopy of metallocenes has been summarized in the preceding paper. We now report vibrationally resolved emission spectra induced by irradiation with a tunable pulsed laser. We deduce excitation spectra from the variation in the area of individual peaks of the dispersed emission spectra as a function of excitation wavelength. Some of the results presented here have been described in preliminary communications. ${ }^{8,9}$

\section{Experimental Section}

The experimental setup for LIF is described in detail in the preceding paper. ${ }^{3} \quad \mathrm{MoCp}_{2} \mathrm{H}_{2}$ and $\mathrm{WCp}_{2} \mathrm{H}_{2}$ were synthesized by

\footnotetext{
${ }^{\otimes}$ Abstract published in Advance ACS Abstracts, November 15, 1994.
}

standard methods. ${ }^{10} \mathrm{MoCp}_{2} \mathrm{H}_{2}$ was cocondensed with matrix gas for ca. $130 \mathrm{~min}$ with the sample held at $310-313 \mathrm{~K}$ and the window at $20 \mathrm{~K}$. The matrix was then cooled to $12 \mathrm{~K}$ before photolyzing for $60 \min (\lambda>200 \mathrm{~nm})$. For $\mathrm{WCp}_{2} \mathrm{H}_{2}$, the sublimation temperature was $318 \mathrm{~K}$ and photolysis time $30 \mathrm{~min}$. In each experiment, it was verified that emission intensity varied linearly with laser energy.

UV/vis and IR absorption spectra of the metallocenes were determined with a matrix apparatus which has been described elsewhere. ${ }^{11} \mathrm{UV} / \mathrm{vis}$ spectra were recorded on a Perkin-Elmer Lambda 7G spectrometer (resolution $0.25 \mathrm{~nm}$ ) and IR spectra on a Mattson/Unicam RS FTIR spectrometer (resolution 1 $\mathrm{cm}^{-1}$ ).

\section{Results}

1. $\mathrm{WCp}_{2}$ in Nitrogen Matrices. The formation of $\mathrm{WCp}_{2}$ by photolysis of $\mathrm{WC}_{2} \mathrm{H}_{2}$ in a nitrogen matrix is illustrated by the difference IR spectrum in Figure 1. The intense band at $3238 \mathrm{~cm}^{-1}$ is assigned as an electronic transition between spinorbit substates, first seen in argon matrices. ${ }^{5,6}$ The figure also shows the growth of the ring-breathing $\left(1085 \mathrm{~cm}^{-1}\right)$ and $\mathrm{C}-\mathrm{H}$ deformation $\left(981,971 \mathrm{~cm}^{-1}\right.$ split) modes of $\mathrm{WCp}_{2}$ and the loss of $\mathrm{W}-\mathrm{H}$ modes of the precursor at ca. $1900 \mathrm{~cm}^{-1} .12$ The UV/ vis absorption spectrum of $\mathrm{WCp}_{2}$ shows the structured $\mathrm{LMCT}$ transition between 370 and $405 \mathrm{~nm}$. The absorption spectrum before annealing shows three clear progressions in the ringmetal-ring symmetric stretching mode, $v_{4}{ }^{\prime}$, of ca. $319 \mathrm{~cm}^{-1}$, arising from $\mathrm{WCp}_{2}$ in three distinct sites/conformers labeled $\alpha$, $\beta$, and $\gamma$ (Figure 2a; Table I, supplementary material). However, the site structure is simplified into two dominant components, split by ca. $90 \mathrm{~cm}^{-1}$, when the matrix is warmed to $30 \mathrm{~K}$ and subsequently recooled (Figure $2 \mathrm{~b}$ ). One component comes close to wavelengths of $\beta$ site absorption, whereas the other site is quite new $(\delta)$. The separation between successive members of each progression, $v_{4}^{\prime}$, is about $314 \mathrm{~cm}^{-1}$ (Table I, supplementary material).

The structure in this spectrum and others in this paper is labeled as follows: upper case letters refer to a progression series, " $\mathrm{A}$ " is the series $n v_{4}(n=0,1,2, \ldots)$ and " $\mathrm{B}$ " is the combination series due to $v_{3}+n v_{4}$; Greek superscripts symbolize a particular site/conformer; the numerals correspond to a particular overtone of the progression. For example, $\mathrm{A}^{\alpha_{3}}$ 


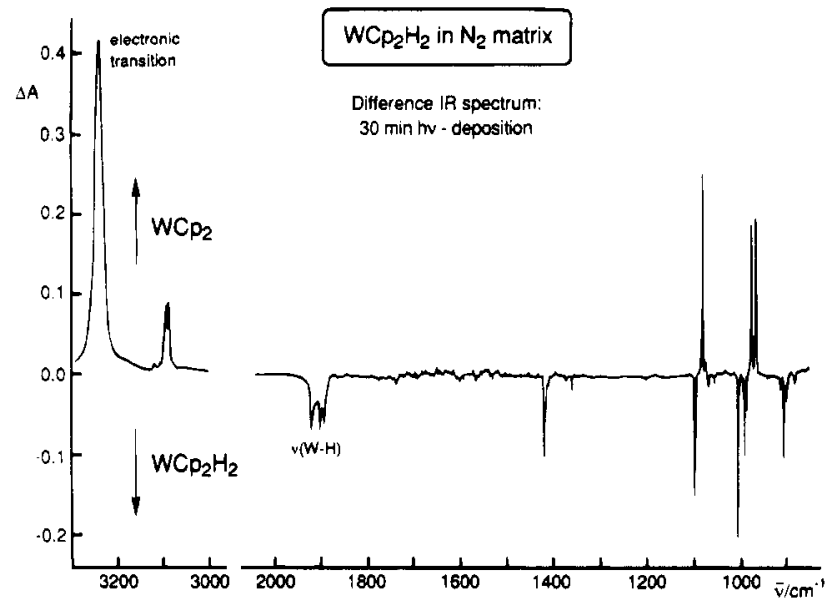

Figure 1. $W \mathrm{Wp}_{2} \mathrm{H}_{2}$ in a nitrogen matrix at $12 \mathrm{~K}$, after 30 -min photolysis $\lambda>200 \mathrm{~nm}$. The IR difference spectrum shows the formation of $\mathrm{WCp}_{2}$ (positive absorbances) and depletion of the $\mathrm{WC}_{2} \mathrm{H}_{2}$ precursor (negative absorbances).

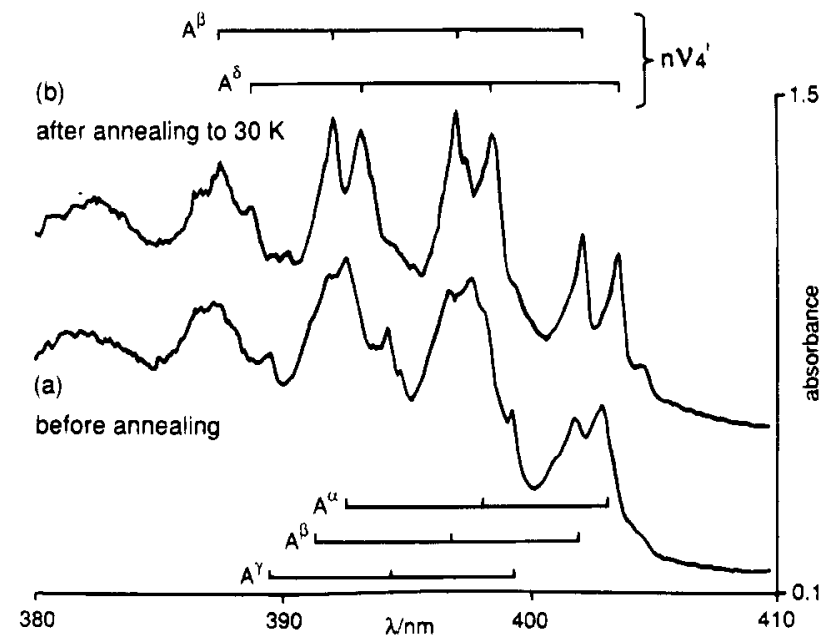

Figure 2. UV/vis absorption spectra of (a) $\mathrm{WCp}_{2}$ obtained after deposition of $\mathrm{WCp}_{2} \mathrm{H}_{2}$ with nitrogen followed by 1-h photolysis, $\lambda>$ $200 \mathrm{~nm}$, and (b) WCp after annealing to $30 \mathrm{~K}$ and recooling to $12 \mathrm{~K}$. The labels $A^{\beta}$ and $A^{\delta}$ refer to the annealed spectrum and indicate progressions in $\nu_{4}^{\prime}$.

symbolizes the third overtone $(v=3-0)$ in the $v_{4}$ progression of site/conformer $\alpha$. As for rhenocene, only three vibrations are involved in the vibrational progressions. They are the totally symmetric modes, $v_{4}, v_{3}$, and $v_{2}$, corresponding to ring-metalring stretching, $\mathrm{C}-\mathrm{H}$ deformation and ring-breathing, respectively. ${ }^{12}$

Irradiation into the LMCT band of an unannealed matrix excites an intense emission spectrum (Table II, supplementary material) with a progression in $\nu_{4}$ " for the three sites/conformers, $\alpha, \beta$, and $\gamma{ }^{9}$ The $(0,0)$ bands in emission for these sites/ conformers are shifted between 25 and $39 \mathrm{~cm}^{-1}$ to lower energy than the corresponding features in the unannealed absorption spectrum. The relative intensity of $\alpha, \beta$, and $\gamma$ is dependent on the excitation wavelength but no component may be excited exclusively. The mean value of $\boldsymbol{v}_{4}{ }^{\prime \prime}$ from all components is $318 \mathrm{~cm}^{-1}$, very close to the value of $\nu_{4}^{\prime}$ obtained from the absorption spectra. A value of $v_{3}{ }^{\prime \prime}$ of $797 \mathrm{~cm}^{-1}$ is measured from this spectrum (see Table II, supplementary material).

The emission spectra show dramatic changes when the matrix is annealed. Irradiation at $392.1 \mathrm{~nm}$, which corresponds to the $\mathrm{A}^{\beta} 2$ absorption band, induces fluorescence from the $\mathrm{A}^{\beta}$ site only (Figure 3a). A combination progression $\mathrm{B}\left(\nu_{3}{ }^{\prime \prime}+n \nu_{4}{ }^{\prime \prime}\right)$ is easily identified, yet there is no clear peak that can be assigned to

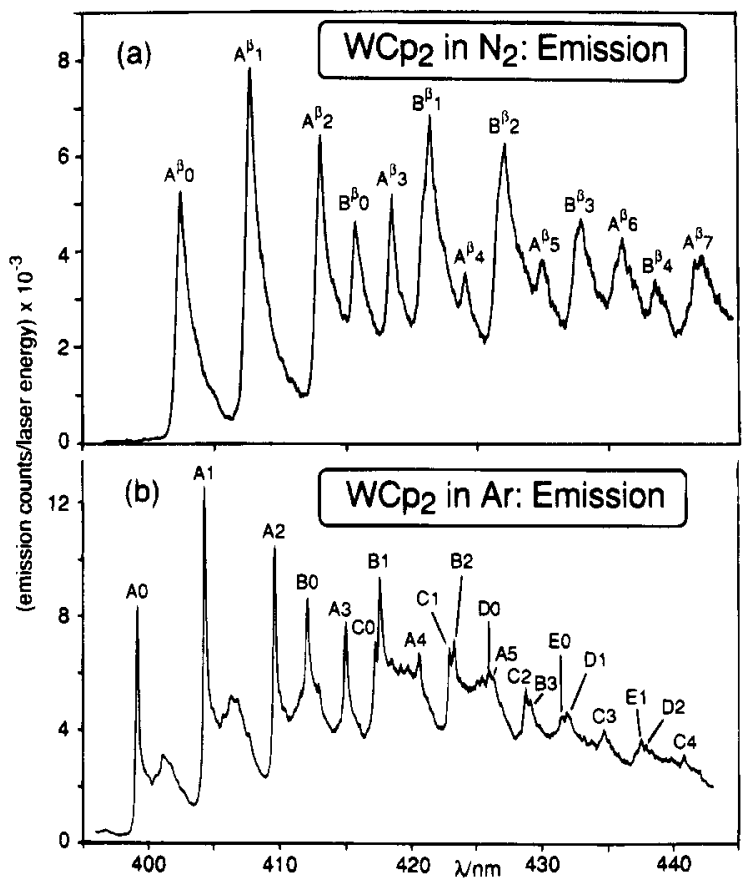

Figure 3. (a) Emission spectrum of $\mathrm{WCp}_{2}$ in a nitrogen matrix at 12 $\mathrm{K}$ after annealing, $\lambda_{\mathrm{ex}}=392.1 \mathrm{~nm}$. (b) Emission spectrum of $\mathrm{WCp}_{2}$ in an argon matrix at $12 \mathrm{~K}, \lambda_{\mathrm{em}}=394.3 \mathrm{~nm}$.

$v_{2}^{\prime \prime}$. No such well-resolved emission spectrum could be obtained prior to annealing with any excitation wavelength. The spectrum is comparable to that of $\mathrm{ReCp}_{2}$, although the bands are much broader (fwhm $=73 \mathrm{~cm}^{-1}$; cf. ca. $20 \mathrm{~cm}^{-1}$ for $R e C p_{2}$ ). Figure $3 \mathrm{~b}$ shows the corresponding spectrum in an argon matrix (see below).

The changes with excitation wavelength that occur in the emission spectra of annealed samples are more subtle than encountered in the $\mathrm{ReCp}_{2}$ system. Emission from the $\beta$-series is detected even if $\gamma$-or $\delta$-series absorption bands are irradiated. Emission from the $\gamma$-series is also observed on irradiation into the $\gamma$-series absorption bands, but emission from the $\delta$-series is very weak, even when the $\delta$-series absorption bands are irradiated directly. These results are suggestive either of energy transfer between sites/conformers or of interconversion between sites.

It is harder to record a reliable excitation spectrum for $\mathrm{WCp}_{2}$ than for $\mathrm{ReCp}_{2}$ because the laser dyes needed to excite emission in the range $350-400 \mathrm{~nm}$ work less efficiently than in the range 450-500 nm. The excitation profile of the $\mathrm{A}^{\beta} 1$ emission band reproduces the positions of the absorption bands of the $\beta$-site well. Despite the selectivity for the $\beta$ site, the excitation spectrum offers no significant improvement in resolution compared to the annealed absorption spectrum.

The decay kinetics of the excited state show that the emission decays within the duration of the laser pulse. This result allows only an upper limit to be set on the lifetime, $\tau$, of $10 \mathrm{~ns}$.

2. WCp $_{2}$ in Argon Matrices. The LMCT absorption band of $\mathrm{WCp}_{2}$ in an argon matrix at $12 \mathrm{~K}$ is slightly blue-shifted in energy compared to that in nitrogen. The vibrational band spacing is ca. $321 \mathrm{~cm}^{-1}$, similar to that determined in nitrogen matrices, but the fine structure $\left(37-75 \mathrm{~cm}^{-1}\right)$ is much less marked and shows no substantial changes when the matrix is annealed. ${ }^{5}$ Irradiation into the LMCT absorption band leads to intense emission (Figure $3 \mathrm{~b}$, Table 3 ). The emission spectrum consists of a sharp and a broad component, separated by 120 $\mathrm{cm}^{-1}$. The fundamentals $v_{4}{ }^{\prime \prime}, \nu_{3}{ }^{\prime \prime}$, and $\nu_{2}{ }^{\prime \prime}$ are measured from the $\mathrm{A}, \mathrm{B}$, and $\mathrm{C}$ progressions, respectively (Figure $3 \mathrm{~b}$ ). 


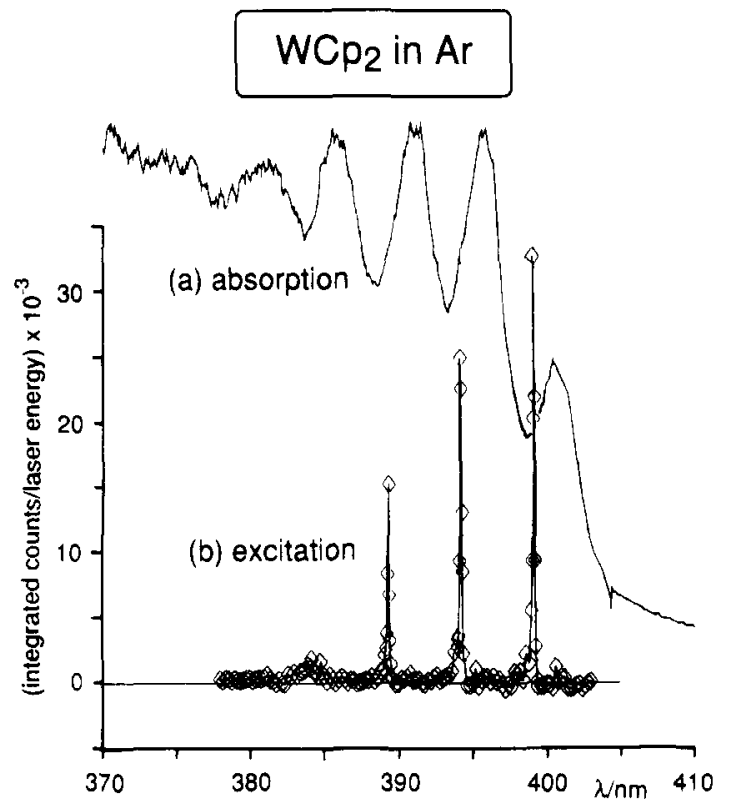

Figure 4. Spectra of $\mathrm{WCp}_{2}$ isolated in an argon matrix at $12 \mathrm{~K}$. (a) Absorption spectrum; (b) excitation spectrum determined from variation of the area of the $\mathrm{A} 2$ emission band with excitation wavelength.

TABLE 3: Emission Spectrum for $\mathrm{WCp}_{2}$ in an Argon Matrix, $\lambda_{\mathrm{ex}}=394.3 \mathrm{~nm}$ (See Figure 3b)

\begin{tabular}{|c|c|c|c|c|c|}
\hline$\lambda, \mathrm{nm}$ & $\bar{v}, \mathrm{~cm}^{-1}$ & $\begin{array}{c}\Delta \bar{\nu}, \mathrm{cm}^{-1} \\
\text { (from origin) }\end{array}$ & label & assgt & interval, $\mathrm{cm}^{-1}$ \\
\hline 399.16 & 25053 & 0 & $\mathrm{~A} 0$ & $\mathrm{~T}_{0}$ & 0 \\
\hline 404.31 & 24734 & 319 & $\mathrm{~A} 1$ & $v_{4}^{\prime \prime}$ & A $0-319$ \\
\hline 409.64 & 24412 & 641 & $\mathrm{~A} 2$ & $2 v_{4}^{\prime \prime}$ & $\mathrm{A} 1-322$ \\
\hline 412.16 & 24262 & 791 & BO & $v_{3}^{\prime \prime}$ & $\mathrm{T}_{0}-791$ \\
\hline 415.04 & 24094 & 959 & A3 & $3 v_{4}^{\prime \prime}$ & $A 2-318$ \\
\hline 417.28 & 23965 & 1088 & $\mathrm{CO}$ & $v_{2}^{\prime \prime}$ & $\mathrm{T}_{0}-1088$ \\
\hline 417.68 & 23942 & 1111 & B1 & $v_{3}^{\prime \prime}+v_{4}^{\prime \prime}$ & $\mathrm{B} 0-320$ \\
\hline 420.6 & 23774 & 1279 & A4 & $4 v_{4}^{\prime \prime}$ & $A 3-320$ \\
\hline 423.0 & 23643 & 1410 & $\mathrm{C} 1$ & $v_{2}^{\prime \prime}+v_{4}^{\prime \prime}$ & $\mathrm{C} 0-322$ \\
\hline 423.3 & 23624 & 1429 & B2 & $v_{3}^{\prime \prime}+2 v_{4}^{\prime \prime}$ & B1 -318 \\
\hline 426.0 & 23473 & 1580 & D0 & $2 v_{3}^{\prime \prime}$ & B0 -789 \\
\hline 426.4 & 23455 & 1598 & A5 & $5 v_{4}^{\prime \prime}$ & A4 -319 \\
\hline 428.8 & 23323 & 1730 & $\mathrm{C} 2$ & $v_{2}^{\prime \prime}+2 v_{4}^{\prime \prime}$ & $\mathrm{Cl}-320$ \\
\hline 429.1 & 23303 & 1750 & B3 & $v_{3}^{\prime \prime}+3 v_{4}^{\prime \prime}$ & $\mathrm{B} 2-321$ \\
\hline 431.5 & 23175 & 1878 & E0 & $?$ & $\mathrm{~T}_{0}-1878$ \\
\hline 431.9 & 23156 & 1897 & D1 & $2 v_{3}^{\prime \prime}+v_{4}^{\prime \prime}$ & D $0-317$ \\
\hline 434.7 & 23004 & 2049 & $\mathrm{C} 3$ & $v_{2}^{\prime \prime}+3 v_{4}^{\prime \prime}$ & $C 2-319$ \\
\hline 437.6 & 22854 & 2199 & $\mathrm{E} 1$ & & $\mathrm{E} 0-321$ \\
\hline 437.9 & 22835 & 2218 & D2 & $2 v_{3}^{\prime \prime}+2 v_{4}^{\prime \prime}$ & D1 -321 \\
\hline 440.8 & 22686 & 2367 & $\mathrm{C} 4$ & $v_{2}^{\prime \prime}+4 v_{4}^{\prime \prime}$ & C3 -318 \\
\hline
\end{tabular}

An excitation profile of the A2 band area is shown as Figure 4b (Table 4). Compared to the absorption spectrum (Figure $4 a)$, the excitation profile is much more highly resolved with a clear progression in $v_{4}{ }^{\prime}$. The $(0,0)$ band positions in excitation and emission are coincident. However, the intensity profile of the excitation maxima does not resemble the intensity profile of the absorption and emission spectra: there is no clear $v_{3}^{\prime}$ band and the emission intensity decreases monotonically with vibrational quantum number. The $\mathrm{A} 3$ emission intensity is very low relative to $\mathrm{A} 2$, whereas the $\mathrm{A} 3$ absorption intensity is still high.

Expansions of the A1 transition show that the excitation band is narrower ( $\mathrm{fwhm} \approx 10 \mathrm{~cm}^{-1}$, Figure $5 \mathrm{a}$ ) than the equivalent band in the emission spectrum (fwhm $=17 \mathrm{~cm}^{-1}$, Figure $5 \mathrm{~b}$ ). The broad component of the emission spectrum is conspicuous in emission but is not seen in excitation, as it has been effectively subtracted out. Both excitation and emission bands are more symmetric than those seen in for $\operatorname{ReCp}_{2}$.
TABLE 4: Excitation Spectrum of the A2 Emission Band of $\mathrm{WCp}_{2}$ in Argon Matrices (See Figure 4b)

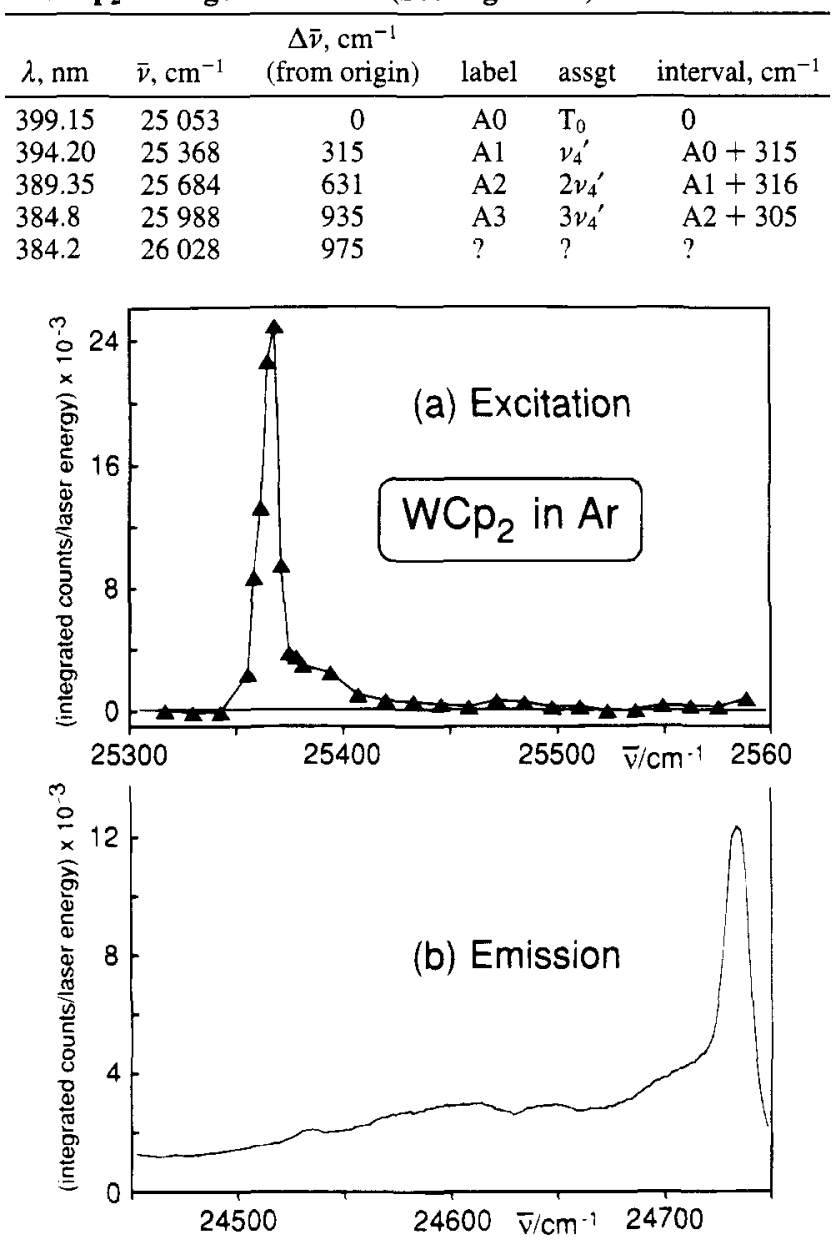

Figure 5. (a) Expanded excitation spectrum of $\mathrm{WCp}_{2}$ in an argon matrix showing the $\mathrm{A} 1(1-0)$ band only. (b) Expanded emission spectrum of $\mathrm{WCp}_{2}$ in an argon matrix at $12 \mathrm{~K}$, showing just the $\mathrm{A} 1$ $(0 \rightarrow 1)$ transition $\left(\lambda_{e x}=399.15 \mathrm{~nm}\right)$.

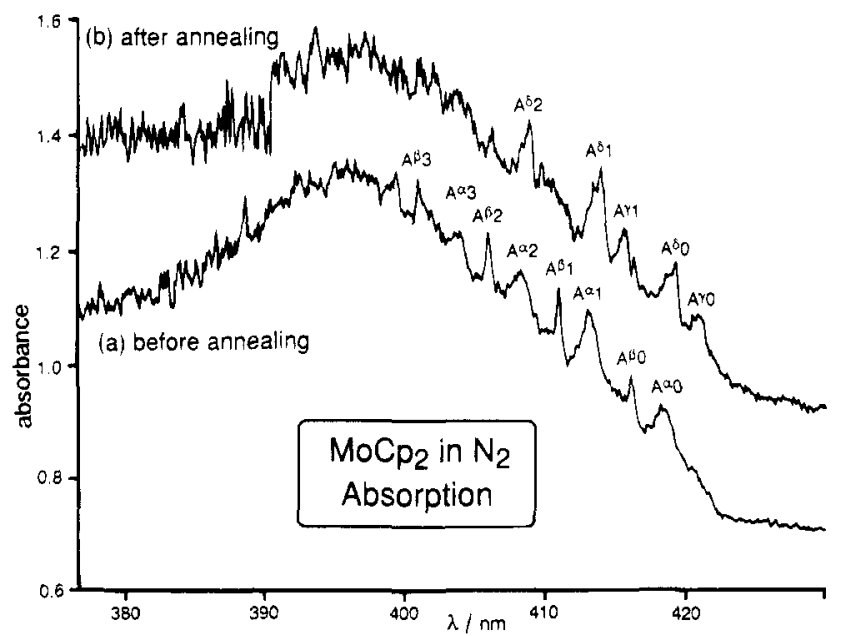

Figure 6. UV/vis absorption spectrum for $\mathrm{MoCp}_{2}$ in a nitrogen matrix at $12 \mathrm{~K}$ : (a) before annealing, (b) after annealing to $30 \mathrm{~K}$ and recooling.

3. $\mathrm{MoCp}_{2}$ in Nitrogen Matrices. The LMCT transition of $\mathrm{MoCp}_{2}$ in a nitrogen matrix has its onset ca. $16 \mathrm{~nm}$ to longer wavelength than that of $\mathrm{WCp}_{2}$. The absorption band is also appreciably broader than that of the tungsten analogue (Figure 6; Table $\mathrm{V}$, supplementary material). Prior to annealing, the absorption spectrum contains two progressions, $\mathrm{A}^{\alpha}$ and $\mathrm{A}^{\beta}$, separated by ca. $140 \mathrm{~cm}^{-1}$ (Figure $6 \mathrm{a}$ ). The interval between successive members of each progression is about $300 \mathrm{~cm}^{-1}$ and 


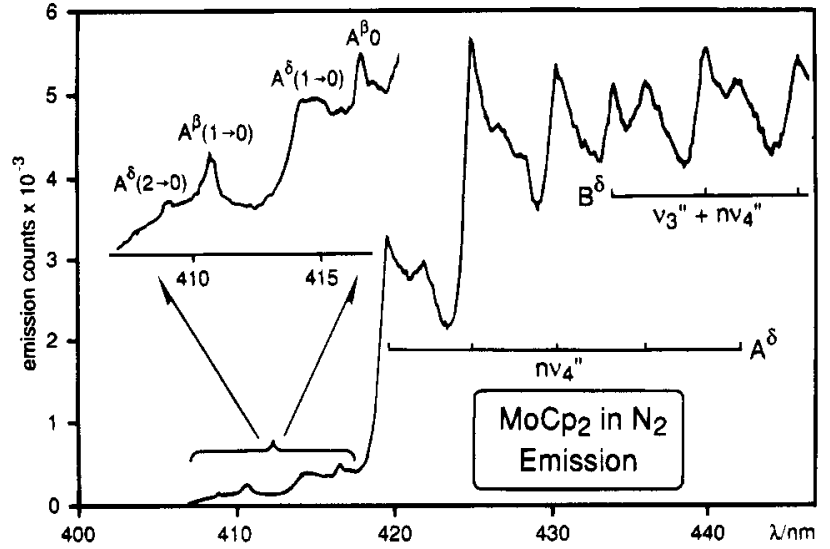

Figure 7. Emission spectrum of $\mathrm{MoCp}_{2}$ in a nitrogen matrix at $12 \mathrm{~K}$ after annealing to $30 \mathrm{~K}$ and recooling $\left(\lambda_{\mathrm{ex}}=402.0 \mathrm{~nm}\right)$. The inset shows an expansion of the short-wavelength region including unrelaxed emission.
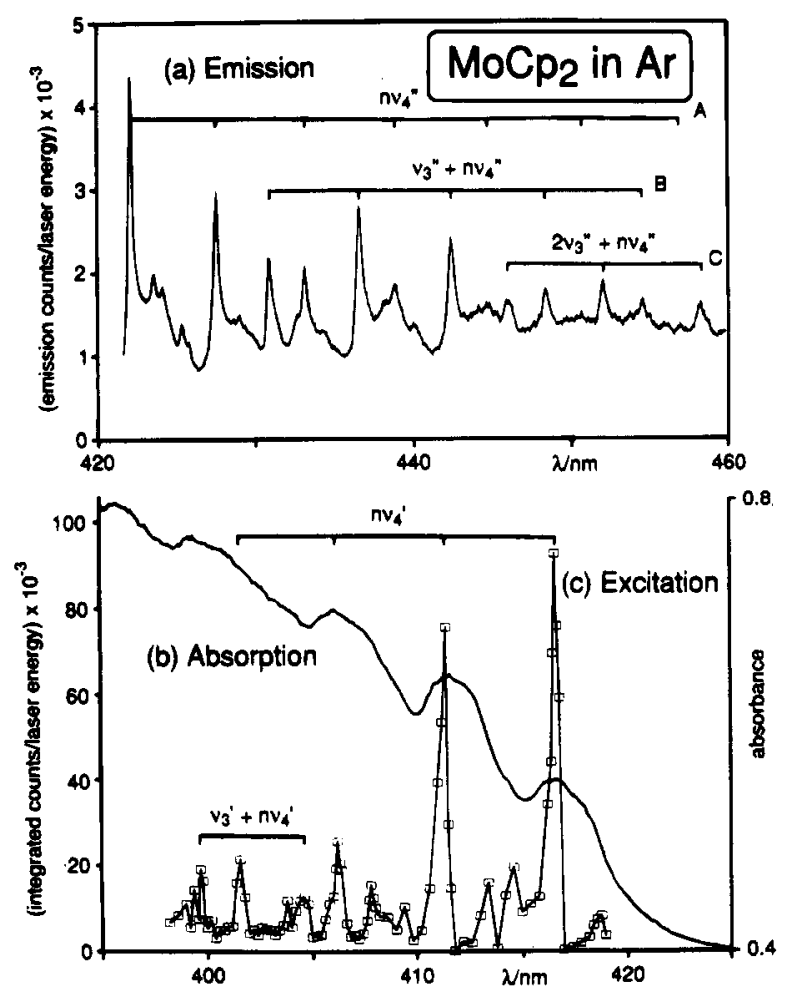

Figure 8. (a) Emission spectrum of $\mathrm{MoCp}_{2}$ in an argon matrix at 12 K. (b) UV/vis absorption spectrum of $\mathrm{MoCp}_{2}$. (c) Excitation spectrum determined from the variation of the area of the A2 emission band with excitation wavelength.

corresponds to $v_{4}^{\prime}$. When the matrix is annealed (Figure $6 \mathrm{~b}$ ) two different series, $\mathbf{A}^{\gamma}$ and $\mathrm{A}^{\delta}$, are seen. Each series appears to be superimposed upon a much broader, unstructured band.

Irradiation into the LMCT band produces relatively poorly resolved fluorescence spectra regardless of whether the matrix has been annealed (Figure 7; Table VI, supplementary material). The emission spectrum shows the $v_{4}$ " progression and the combination series due to $v_{3}{ }^{\prime \prime}+n v_{4}{ }^{\prime \prime}$. The onset of the main emission is at $419.5 \mathrm{~nm}$, close to the position of the $A^{\delta} 1$ absorption band. Multiple components are identified when the excitation wavelength is changed, but the large proportion of unstructured emission remains.

The weak emission bands appearing at shorter wavelengths than the assigned electronic origin $\mathrm{A}^{\delta} 0$ are enlarged in the inset of Figure 7. The longest wavelength of these bands arises from fully relaxed fluorescence: $\mathrm{A}^{\beta} 0\left(\lambda_{\mathrm{em}} \approx 416.1 \mathrm{~nm}\right)$. The other features are observed at shorter wavelengths, suggesting that
TABLE 7: Principal Features of the Emission Spectrum of $\mathrm{MoCp}_{2}$ in an Argon Matrix, $\lambda_{\mathrm{ex}}=416.6 \mathrm{~nm}$ (See Figure 8a)

\begin{tabular}{|c|c|c|c|c|c|}
\hline$\lambda, \mathrm{nm}$ & $\bar{v}, \mathrm{~cm}^{-1}$ & $\begin{array}{c}\Delta \bar{\nu}, \mathrm{cm}^{-1} \\
\text { (from origin) }\end{array}$ & label & assgt & interval, $\mathrm{cm}^{-1}$ \\
\hline $416.6^{a}$ & 24004 & 0 & $A O$ & $T_{0}$ & 0 \\
\hline 42 & 2 & 313 & A1 & $\nu_{4}^{\prime \prime}$ & $\mathrm{T}_{0}-313$ \\
\hline 427 & 2 & 618 & A2 & $2 v_{4}^{\prime \prime}$ & $\mathrm{A} 1-305$ \\
\hline 430.9 & 232 & 797 & B0 & $v_{3}^{\prime \prime}$ & $\mathrm{T}_{0}-797$ \\
\hline 433.2 & 230 & 920 & A3 & $3 v_{4}^{\prime \prime}$ & A $2-302$ \\
\hline 436.6 & 229 & 1100 & B1 & $v_{3}^{\prime \prime}+v_{4}^{\prime \prime}$ & BO -303 \\
\hline 438.9 & 22 & 1220 & A4 & $4 v_{4}^{\prime \prime}$ & A3 -300 \\
\hline 442 & & 05 & B2 & $v_{3}^{\prime \prime}+2 v_{4}^{\prime \prime}$ & B $1-305$ \\
\hline 444.7 & & 1 & A5 & $5 v_{4}^{\prime \prime}$ & $A 4-297$ \\
\hline 446.0 & 224 & 1582 & D0 & $2 v_{3}^{\prime \prime}$ & B $0-785$ \\
\hline 448 & 222 & 1707 & B3 & $v_{3}^{\prime \prime}+3 v_{4}^{\prime \prime}$ & B2 -302 \\
\hline 450.7 & 221 & 1816 & A6 & $6 v_{4}^{\prime \prime}$ & A5 -299 \\
\hline 452.1 & 22119 & 1885 & D1 & $2 v_{3}^{\prime \prime}+v_{4}^{\prime \prime}$ & $\mathrm{CO}-303$ \\
\hline 454.7 & 21993 & 2011 & B4 & $v_{3}^{\prime \prime}+4 v_{4}^{\prime \prime}$ & B3 - 304 \\
\hline 457.1 & & 2127 & A7 & $7 v_{4}^{\prime \prime}$ & A6 -311 \\
\hline 458.4 & 21815 & 2189 & D2 & $2 v_{3}^{\prime \prime}+2 v_{4}^{\prime \prime}$ & $C 1-304$ \\
\hline
\end{tabular}

${ }^{a}$ Position of the $(0,0)$ is taken from the excitation spectrum.

TABLE 8: Excitation Spectrum of $\mathrm{MoCp}_{2}$ in an Argon Matrix (See Figure 8c)

\begin{tabular}{ccclll}
$\lambda, \mathrm{nm}$ & $\bar{\nu}, \mathrm{cm}^{-1}$ & $\begin{array}{c}\Delta \bar{\nu}, \mathrm{cm}^{-1} \\
\text { (from origin) }\end{array}$ & label & \multicolumn{1}{c}{ assgt } & interval, $\mathrm{cm}^{-1}$ \\
\hline 416.6 & 24004 & 0 & $\mathrm{~A} 0$ & $\mathrm{~T}_{0}$ & 0 \\
411.4 & 24307 & 303 & $\mathrm{~A} 1$ & $\nu_{4}{ }^{\prime}$ & $\mathrm{T}_{0}+303$ \\
406.2 & 24618 & 614 & $\mathrm{~A} 2$ & $2 v_{4}{ }^{\prime}$ & $\mathrm{A} 1+311$ \\
404.4 & 24728 & 724 & $\mathrm{~B} 0$ & $v_{3}{ }^{\prime}$ & $\mathrm{T}_{0}+724$ \\
401.2 & 24925 & 921 & $\mathrm{~A} 3$ & $3 v_{4}{ }^{\prime}$ & $\mathrm{A} 2+307$ \\
399.7 & 25019 & 1015 & $\mathrm{~B} 1$ & $v_{3}{ }^{\prime}+v_{4}{ }^{\prime}$ & $\mathrm{B} 0+291$
\end{tabular}

they originate from unrelaxed emission. The proposed transitions are given on Figure 7.

Lifetime measurements of the excited state were attempted, but the duration of the laser pulse again exceeds the emission lifetime, allowing only an upper limit to be set at $10 \mathrm{~ns}$.

4. $\mathrm{MoCp}_{2}$ in Argon Matrices. The absorption spectrum of $\mathrm{MoCp}_{2}$ in an argon matrix ${ }^{5}$ is similar in appearance to that in a nitrogen matrix, although the site structure is less distinct. The best-resolved emission spectra are obtained when exciting into the $(0,0)$ transition of the absorption spectrum (Figure 8a, Table 7). (Note that this figure does not show the $(0,0)$ emission band since it is close to the laser line.) Progression series, $n v_{4}^{\prime \prime}$ (A), $v_{3}{ }^{\prime \prime}+n v_{4}{ }^{\prime \prime}(\mathrm{B})$, and $2 v_{3}{ }^{\prime \prime}+n v_{4}{ }^{\prime \prime}(\mathrm{C})$ are observed. Site structure is apparent in all the spectra recorded, and different features appear to be probed selectively according to the laser wavelength. More congested spectra are obtained when shorter wavelength excitation is used. The spectra all show a substantial unstructured, background fluorescence. Shorter wavelength excitation induces some emission at shorter wavelengths than the $(0,0)$ band, akin to that seen in a nitrogen matrix.

An excitation spectrum may be obtained by recording the area of the A2 emission band as a function of laser wavelength and energy (Figure $8 \mathrm{c}$, Table 8 ). The excitation profile shows a dramatic improvement in resolution when compared to the absorption spectrum (Figure 8b), allowing values for the excitedstate vibrations $\nu_{4}^{\prime}$ and $\nu_{3}^{\prime}$ to be obtained. Notice that the excitation spectrum gives the impression that short-wavelength excitation does not induce emission. In fact, substantial fluorescence is observed, but it is poorly resolved and the area of the A2 band cannot be measured reliably.

The lifetime of the excited state proved shorter than the duration of the laser pulse (i.e., $<10 \mathrm{~ns}$ ).

\section{Discussion}

The $\mathrm{d}^{4}$ metallocenes, $\mathrm{WCp}_{2}$ and $\mathrm{MoCp}_{2}$, exhibit intense structured emission from their LMCT excited states. The LIF 
TABLE 9: Progression Frequencies $\left(\bar{v}, \mathrm{~cm}^{-1}\right)$ of Metallocenes in the Ground and Excited States with the Estimated Standard Error (95\% Probability), Where Available, in Parentheses

\begin{tabular}{cccccccc}
\hline compound & matrix/phase & \multicolumn{1}{c}{$v_{4}{ }^{\prime \prime}$} & \multicolumn{1}{c}{$v_{4}{ }^{\prime}$} & $v_{3}{ }^{\prime \prime}$ & $\nu_{3}{ }^{\prime}$ & $v_{2}{ }^{\prime \prime}$ & $v_{2}{ }^{\prime}$ \\
\hline $\mathrm{ReCp}_{2}$ & $\mathrm{Ar}$ & $323(7)$ & $340(4)$ & 818 & 745 & 1097 & 1060 \\
& $\mathrm{~N}_{2}$ & $325(5)$ & $342(3)$ & 826 & 754 & 1100 & 1063 \\
$\mathrm{WCp}_{2}$ & $\mathrm{Ar}$ & $320(3)$ & 316 & 790 & & 1088 & \\
& $\mathrm{~N}_{2}{ }^{a}$ & $318(6)$ & $316(12)$ & 797 & & & \\
& $\mathrm{~N}_{2}{ }^{b}$ & $318(11)$ & $313(24)$ & 789 & & & \\
$\mathrm{MoCp}_{2}$ & $\mathrm{Ar}$ & $303(7)$ & 307 & 791 & 724 & & \\
& $\mathrm{~N}_{2}$ & $300(21)$ & $302(12)$ & 791 & & & \\
$\mathrm{RuCp}_{2}{ }^{c}$ & crystal & 333 & 279 & & & 1104 & \\
$\mathrm{ZnCp}^{d}$ & gas & 254 & 279 & 772 & 737 & 1001 & 953
\end{tabular}

${ }^{a}$ Prior to annealing. ${ }^{b}$ After annealing. ${ }^{c}$ From ref $14 .{ }^{d}$ From ref 13.

spectra have many features in common with the spectra of $\mathrm{ReCp}_{2}$. The emission occurs from the same state as that probed by the laser, with $(0,0)$ bands close to coincidence in emission, absorption, and excitation. The vibrational progression in the ring-metal-ring symmetric stretching mode, $n v_{4}$, dominates the spectrum, with weaker progressions from $v_{3}+n v_{4}$ and sometimes, $v_{2}+n v_{4}$ or $2 v_{3}+n v_{4}$. The spectra of $\mathrm{WCp}_{2}$ and $\mathrm{MoCp}_{2}$ are complicated by the presence of multiple trapping sites and/or conformers. By judicious choice of conditions, it is possible to obtain emission and excitation spectra dominated by a single site/conformer. Some of the excitation spectra are much sharper than the corresponding absorption spectra.

There are also several features of the spectra which differ significantly from those of $\mathrm{ReCp}_{2}$, some of which are described in more detail below: (i) the emission lifetimes are all too short to measure with the current apparatus $(<10 \mathrm{~ns}$, compared with $72 \mathrm{~ns}$ for $\mathrm{ReCp}_{2}$ ); (ii) the differences between ground- and excited-state values of $v_{4}$ are very small $\left(\leq 4 \mathrm{~cm}^{-1}\right)$; (iii) the narrowest emission and excitation bands of $\mathrm{MoCp}_{2}$ and $\mathrm{WCp}_{2}$ (in argon matrices) are close to symmetrical, unlike the skew shape observed for $\mathrm{ReCp}_{2}$; (iv) the intensity profiles of the emission and excitation spectra, especially of $\mathrm{WCp}_{2}$ in $\mathrm{Ar}$, are not mirror images; (v) the spectra of $\mathrm{MoCp}_{2}$ show evidence for unrelaxed emission.

1. Vibrational Fine Structure. The totally symmetric vibrational frequencies determined from the LIF spectra are listed in Table 9 together with values for other metallocenes. Although the spectra of $\mathrm{MoCp}_{2}$ and $\mathrm{WCp}_{2}$ are dominated by progressions in $v_{4}$, the differences between ground- and excitedstate values of $v_{4}$ are so small $\left(\leq 4 \mathrm{~cm}^{-1}\right)$ as to be insignificant when errors are taken into account. It proved possible to determine $v_{3}$ " in all emission spectra, but the corresponding value of $v_{3}^{\prime}$ was determined only for $\mathrm{MoCp} 2$ in argon matrices. In that case, a reduction of $67 \mathrm{~cm}^{-1}(8.4 \%)$ was found. Only one value of $\nu_{2}^{\prime \prime}$ was measured and none of $\nu_{2}^{\prime}$. Since $v_{4}$ is the progression-forming mode, there must be a change in the metalring bond length in the excited state. The lack of a corresponding change in $v_{4}$ indicates that $v_{4}$ does not correlate simply with bond length and that there must also be changes in coupling between vibrations in the excited state.

The symmetric band shape with fwhm of $10-20 \mathrm{~cm}^{-1}$ found in the sharpest spectra of $\mathrm{WCp}_{2}$ in solid argon implies that there is no coupling either to matrix phonons or torsional overtones as postulated to explain the skew shape of rhenocene bands.

It is valuable to compare the changes in the frequencies between ground and excited states for the range of metallocenes (Table 9). The transition involved in the cases of $\mathrm{ReCp}_{2}$, $\mathrm{MoCp} \mathrm{p}_{2}$, and $\mathrm{WCp}_{2}$ transfers an electron from a ligand $\pi$-orbital to a metal-ligand bonding orbital. For $\mathrm{ReCp}_{2}$ this results in an increase in $v_{4}$, but for the $\mathrm{d}^{4}$ metallocenes, there is essentially no change. For $\mathrm{ReCp}_{2}$ there is also a substantial fall in $\nu_{3}$ and $\nu_{2}$. The data for the $\mathrm{d}^{4}$ metallocenes are incomplete, only allowing us to state that there is a similar reduction in $\nu_{3}$ for $\mathrm{MoCp}_{2}$. The transition involved in emission from $\mathrm{ZnCp}$ also has LMCT character, ${ }^{13}$ though this time the electron is transferred to a metal p-orbital. The changes in frequency are remarkably similar to those found for $\mathrm{ReCp}_{2}$ in spite of the drastic difference in electron configuration and the reduced value of $v_{4}$. In contrast, the emission from crystalline $\mathrm{RuCp}_{2}$ arises from a spin-forbidden ligand-field band, ${ }^{14}$ so the electron is transferred to an orbital which is strongly metal-ligand antibonding. As a result, the value of $v_{4}$ falls by $54 \mathrm{~cm}^{-1}(16 \%)$. The relation between the changes in the frequency and the changes in geometry will be developed in a subsequent paper via Franck-Condon analysis.

2. Unrelaxed Emission. The emission spectra of $\mathrm{MoCp}_{2}$ in nitrogen matrices show weak features to high energy of the electronic origin with frequencies which fit with emission from $v^{\prime}=1$ levels. This observation is consistent with a very short emission lifetime and a comparable relaxation time. The broadening of emission spectra when higher vibrational quanta are probed may be another manifestation of unrelaxed emission, since it would give rise to multiple overlapping bands. It may also contribute to the broadening of the high-energy features of the excitation spectra (e.g., Figure 4) so the excitation profile does not mirror the emission profile. For comparison, unrelaxed emission is much more important in the gas phase, as has been observed for $\mathrm{ZnCp} .{ }^{13}$

\section{Conclusions}

The $\mathrm{d}^{4}$ metallocenes $M o C p_{2}$ and $\mathrm{WCp}_{2}$ isolated in $\mathrm{N}_{2}$ and Ar matrices exhibit well-resolved fluorescence spectra when excited with a pulsed tunable laser. Both absorption and emission involve the same fully allowed LMCT excited state with lifetime $<10 \mathrm{~ns}$. The spectra are complicated by the presence of multiple sites/conformers, but emission spectra of a single site can be obtained with suitable choice of matrix and excitation wavelength. Similarly, single-site excitation spectra can be obtained with suitable choice of emission maximum. The spectra are dominated by progression series in the symmetric ring-metal-ring stretching mode, $n v_{4}$, with additional progressions in $v_{3}+n v_{4}, v_{2}+n v_{4}$, and $2 v_{3}+n v_{4}$. Nevertheless, the changes in $\nu_{4}$ between ground and excited states are $\leq 4 \mathrm{~cm}^{-1}(\leq 1.3 \%)$, implying that the vibrational frequencies do not correlate well with the geometric coordinate.

Acknowledgment. We are particularly grateful to Dr. A. W. Parker and S. Tavender of the Rutherford-Appleton Laboratory for their support. We also appreciate the help given by Dr. S. E. J. Bell, S. A. Brough, and Dr. A. McCamley. We thank Prof. M. L. H. Green for a sample of $\mathrm{WCp}_{2} \mathrm{H}_{2}$. This work was supported by SERC, The Royal Society, British Gas and the European Commission.

Supplementary Material Available: Tables I, II, V, VI: $\mathrm{UV} / \mathrm{vis}$ absorption and emission spectra for $\mathrm{WCp}_{2}$ and $\mathrm{MoCp}_{2}$ in nitrogen matrices ( 5 pages). Ordering information appears on any current masthead page.

\section{References and Notes}

(1) Present address: Department of Chemistry, St. Patrick's College, Maynooth, Ireland.

(2) Photoprocesses in Transition Metal Complexes, Biosystems and other Molecules. Experiment and Theory; Kochanski, E., Ed.; NATO ASI Series C; Kluwer Academic Publishers: Dordrecht, 1992; Vol. 376. Tumer, J. J.; Johnson, F. P. A.; Westwell, J. R. Coord. Chem. Rev. 1993, 125, 101

(3) Hill, J. N.; Perutz, R. N.; Rooney, A. D. Preceding paper in this issue. 

453.

(4) Grebenik, P.; Grinter, R.; Perutz, R. N. Chem. Soc. Rev. 1988, 17, (5) Chetwynd-Talbot, J.; Grebenik, P.; Perutz, R. N. Inorg. Chem. 1982, $21,3647$.

(6) Cox, P. A.; Grebenik, P.; Perutz, R. N.; Robinson, M. D.; Grinter, R.; Stern, D. R. Inorg. Chem. 1983, 22, 3614.

(7) Graham, R. G.; Grinter, R.; Perutz, R. N. J. Am. Chem. Soc. 1988. 110,7036 .

(8) Bell, S. E. J.; Hill, J. N.; McCamley, A.; Perutz, R. N. J. Phys. Chem. 1990, 94, 3876.

(9) Perutz, R. N.; Hill, J. N.; McCamley, A. Coord. Chem. Rev. 1991, 111,111 .

(10) Green, M. L. H.; Knowles, P. J. J. Chem. Soc., Perkin Trans. 1 $1973,989$.

(11) Haddleton, D. M.; McCamley, A.; Perutz, R. N. J. Am. Chem. Soc. 1988, $110,1810$.

(12) Aleksanyan, V. T. In Vibrational Spectra and Structure; Durig, J. R., Ed.; Elsevier: Amsterdam, 1982; Vol. 11.

(13) Robles, E. S. J.; Ellis, A. M.; Miller, T. A. J. Phys. Chem. 1992 96, 3247.

(14) Riesen, H.; Krausz, E.; Luginbühl, W.; Biner, M.; Güdel, H. U.; Ludi, A. J. Chem. Phys. 1992, 96, 4131. Wrighton, M. S.; Pdungsap, L.; Morse, D. L. J. Phys. Chem. 1975, 79, 66. Hollingsworth, G. J.; Kim Shin, K.-S.; Zink, J. I. Inorg. Chem. 1990, 29, 2501. 